\title{
Radiographic Parameters in Non-Contrast Computed Tomography Predict the Success of Percutaneous Nephrolithotomy
}

Hayder M. Al-Aridy*

Hayder Q.Al-mosawi ${ }^{* *}$

Zena Abduljabbar***

*Medical College,Kufa University,Department of Urology

${ }^{* * *}$ Medical College,Kufa University,Department of Radiology

****Al-Hilla Teaching Hospital, Ministry of Health

\section{Abstract:}

Aim: To evaluate whether non-contrast Computed Tomogram (CT) parameters (stone density, localization, size \& degree of pelvicalceal system dilatation) predict the outcome of percutaneous Nephrolithotomy (PCNL).

Method: This study included 68 patients (43 male \& 25 female) with renal calculi scheduled for PCNL. They were examined by non-contrast CT to determine calculus size, calculus density, calculus location \& degree of pelvicalceal system dilatation. Ultrasound at scheduled PCNL follow-up one and two months later and undertaken by 2 radiologist at the same unit (HD11XE Philips 2010 unit) checked for residual stones. Stones equal or more than $4 \mathrm{~mm}$ in largest diameter was regarded as significant.

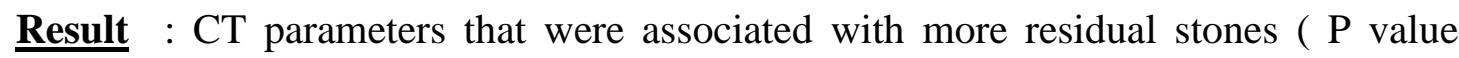
$<0.001$ ) included density less than $700 \mathrm{HU}$, upper calyx location, presence of preoperative hydronephrosis and large stone size.

Conclusion: pre-operative CT can predict the outcome of PCNL. Stone parameters that predict the oucome of PCNL included stone density, less than $700 \mathrm{HU}$, upper calyceal stone, large size stone $\&$ the presence of pre-operative hydronephrosis.

Key wards: computed tomogram parameters, percutaneous nephrolithitomy

\section{Overview}

Percutaneous nephron-lithotomy (PCNL) is the standared treatment for staghorn renal stones especially when other medical and/or surgical treatment methods have failed. Primary assessment of renal stones is usually by non-contrast helical CT. ${ }^{(1)}$ This imaging modality is fast and can accurately detect all types of stones and locations whether in the renal calyces or in the ureter with high sensitivity (95 to 100 percent) and specificity (94 to 96 percent). ${ }^{(2,3)}$ Helical CT scan can also be used to detect renal calyceal stones that are missed on intravenous urography study. ${ }^{(4)}$ 
Many previous studies have shown that CT scan is more accurate as the first line imaging than IVU for patients with loin pain. ${ }^{(5,6)}$ The potential radiation effects of a CT scan has not prevented its use, even in the pediatric setting where CT is used to detect 96 to $100 \%$ of stones. ${ }^{(7)}$ In addition to the diagnosis of renal stones, CT can also accurately depict the extent of calyceal involvement and the site and orientation of the stones which all provide a road map for PCNL tract selection.

It also provides excellent anatomical information on the relationship of the calyceal system to adjacent organs such as the colon, liver, lung bases or spleen that help the surgeon avoid injury to these structures. The proximity of an upper pole calyx to the pleural space can also be delineated by CT enabling a plan of the tract beforehand and avoidance of intra thoracic complications during PCNL. ${ }^{(8)}$

Since 1998 when the multidetector CT was introduced, many advances in technology and post-processing algorithms and imaging workstations have been developed allowing multiplanar and three dimensional assessment that greatly helps urosurgeons fully assess renal stones. In addition to stone volume, the multi-detector highresolution CT coronal reformatted images obtained by the 64-detector CT can also accurately detect the presence and degree of hydronephrosis (i.e., obstruction). ${ }^{(9,10)}$

The CT protocol for urinary stones requires scanning to include the entire urinary system from the upper pole of the kidneys to the base of the urinary bladder. ${ }^{(11)}$

CT scan can also provide information about the stone density which provides information about its uric acid type and is categorized as 200-450 Hounsfield unit(HU); struvite, 600-900 HU; cystine, 600-1100 HU; calcium phosphate, 1200$1600 \mathrm{HU}$; and calcium oxalate monohydrate $1700-2800 \mathrm{HU} .^{(12-13)}$

The two radiolucent stones - Indinavir stones (from anti-retroviral drug) and pure matrix stones are usually undetectable on CT. ${ }^{(14)}$

The objective of this study is to evaluate the preoperative CT factors associated with residual stones after PCNL.

\section{Materials and Method}

In this study 68 patients (43 male \& 25 female) with renal calculi scheduled for PCNL were enrolled from January 2013 to July 2013 at Al Sadder Medical City/Najaf/Iraq. They were examined by non-contrast CT to determine CT parameters (stone density, size, location \& associated PCS dilatation) then followed with ultrasound examination immediately post-operatively then one month \& 2 months after PNCL.

After a 4-h fasting, all patients underwent prone CT studies using a 64-slice CT scanner (Aquillon 64, V4.51 ER 010, Toshiba Medical Systems, Tochigi, Japan). The diagnostic modality of choice in the radiographic evaluation of suspected nephrolithiasis is 5 millimeters sections.

All CT examinations were reviewed by one radiologist experienced in Uro-radiology. Measured variables were: calculus size, calculus density, calculus location \& degree of PCS dilatation. Axial imaging data sets are frequently used in the detection of renal stones. Coronal or sagittal reformatted images were used to supplement the axial 
scans in identifying the exact site of stone impaction. Calculus density was measured on the unenhanced axial studies using a region-of-interest circle (ROI).
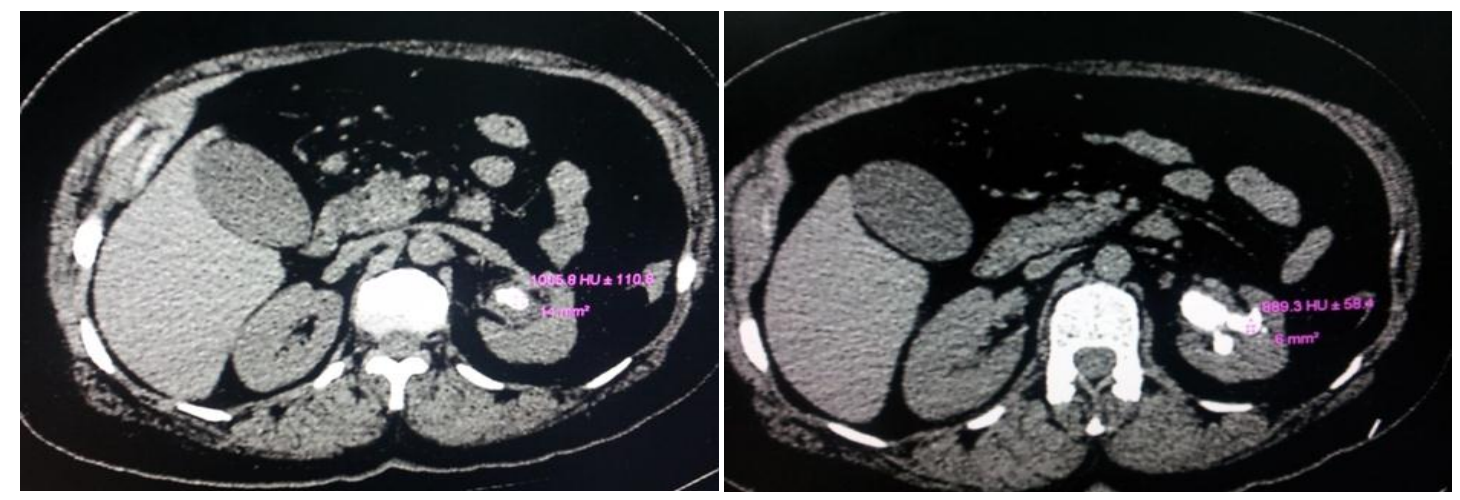

Figure (1) non enhanced axial CT scan show measurement of the density in stag horn stone.

Calculus size was measured on the unenhanced CT as one of the reference standard parameters. The maximal axial and coronal dimensions were measured using measurement calipers on the work station. To reduce measurement error, the mean of three measurements was used.
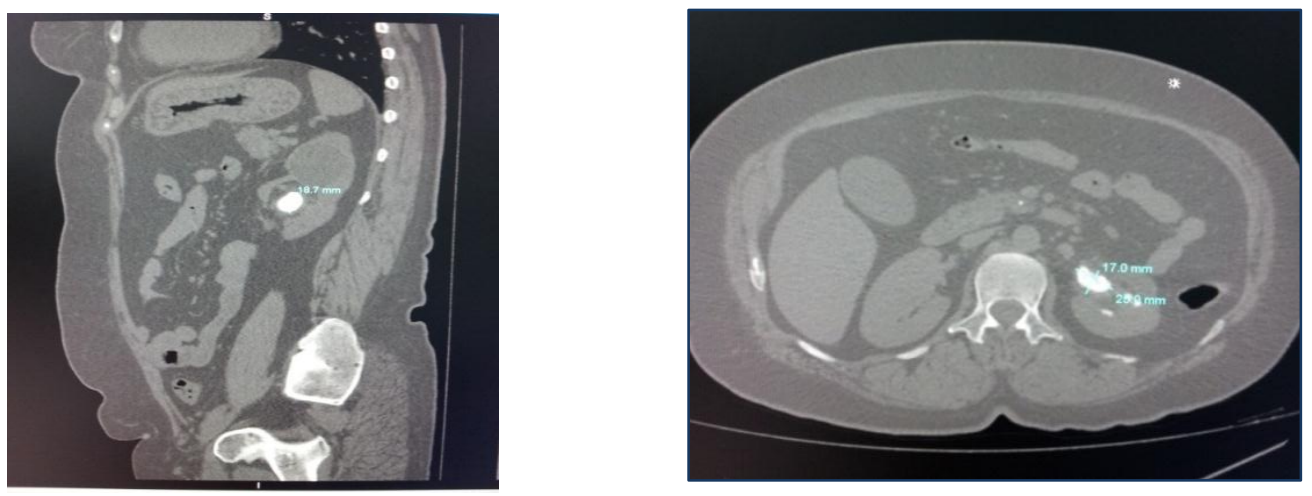

a

$\mathrm{b}$

Figure (2) non contrast CT scan with bone window sagital (a) and axial (b) images showing the measurement of stone volume

CT scans can be used to find the exact location of the stone, as well as to look for anatomical problems that may have led to stone formation. The degree of pelvicalceal system dilatation was assessed preoperatively by unenhanced CT where renal parenchymal thickness decreased and categorized as no dilatation, splitting, mild, moderate and severe dilatation. US was used to detect residual stone immediate post operatively, then one and two months after the PNCL with a residual stone equal 
to or more than $4 \mathrm{~mm}$ in longest diameter regarded as significant. The sonography explorations were done using an HD11XE Philips 2010 unit.

Statistical analysis was done using SPSS (statistical package for social sciences) version 17. Number, percentages, mean, standard deviation as descriptive statistics and person correlation coefficient for correlation between the variables and chi square were used for comparison between categorical data. We set $\mathrm{p}$ value $<0.05$ as significant.

\section{Results:}

The mean age of the patients was 42 years (range 22-61yr) with $43(63.3 \%)$ males and $25(36.7 \%)$ females. Successful resolution was achieved in 48 (70.59\%) patients, mean operation duration was 30-45minutes, the duration of fluoroscopy was $0.4-17$ minutes, and a drop in hematocrit was observed in four patients $(5.89 \%)$ all with large size and hard stones (>1000HU).

In this study patients were divided into two groups : positive residual and and negative residual stone groups with a stone $4 \mathrm{~mm}$ size or less considered a positive residual stone. In the multivariable analysis performed to evaluate the factors that affect surgery success, HU value, the size of the stone and PCS dilatation and localization of the stone were found to be effective predictor factors.

The use of coronal reformatted images in conjunction with axial scans facilitated the differentiation of renal parenchymal calcifications from urinary stones.

We found a significant correlation between $\mathrm{HU}$ and residual stone where a $\mathrm{HU}$ value equal or less than 700 was associated with higher rate of residual stones as shown in table 2. A larger stone size was more likely to lead to residual post-operative stones as shown in tables 1 and 6 . The study also found that the presence of preoperative hydronephrosis had a significant role in determining the success of PCNL as increased PCS dilation was associated with increase chance of post-operative residual stone as shown in table 3. As upper calyceal stone was associated with a higher residual rate than stones in other locations as shown in table 5.

There was a positive significant correlation between HU value and a decrease in hematocrit value $(\mathrm{P}<0.05)$.

Table 1. Relationship between age of the patient, stone density, size and residual stones.

\begin{tabular}{|c|c|c|c|}
\hline \multirow{2}{*}{ Parameter } & Positive residual & Negative residual & \multirow{2}{*}{ P Value } \\
\cline { 2 - 4 } & Mean \pm SD & Mean \pm SD & \\
\hline Age /years & 41.3 & 40.4 & 0.724 \\
\hline $\begin{array}{c}\text { Stone density } \\
\text { (HU) }\end{array}$ & $\mathbf{6 1 8 . 5 \pm 1 0 4 . 0 8}$ & $\mathbf{8 1 7 . 8} \pm \mathbf{1 7 7 . 3 5}$ & $<0.001$ \\
\hline
\end{tabular}




\begin{tabular}{|c|c|c|c|}
\hline $\begin{array}{c}\text { Size } \\
(\mathrm{mm})^{3}\end{array}$ & $35968.75 \pm 23630.54$ & $14856.78 \pm 16301.9$ & $<0.001$ \\
& & & \\
\hline
\end{tabular}

Table 2. The relationship between stone density and residual stone post PCNL.

\begin{tabular}{|c|c|c|c|}
\hline & Density $<700$ & Density $>\mathbf{7 0 0}$ & Total \\
\hline \multirow{2}{*}{$\begin{array}{c}\text { Residual stone } \\
\text { +ve }\end{array}$} & 15 & 5 & 20 \\
\hline \multirow{2}{*}{$\begin{array}{c}\text { Residual stone }- \\
\text { ve }\end{array}$} & $\mathbf{7 5 . 0 \% )}$ & $(\mathbf{2 5 . 0 \% )}$ & $\mathbf{( 1 0 0 . 0 \% )}$ \\
\hline \multirow{2}{*}{ Total } & $\mathbf{2 5 . 0 \% )}$ & $\mathbf{3 6}$ & $\mathbf{4 8}$ \\
\hline & $\mathbf{2 7}$ & $\mathbf{7 5 . 0 \% )}$ & $\mathbf{( 1 0 0 . 0 \% )}$ \\
\hline
\end{tabular}

Sensitivity $=75 \%$, Specificity $=75 \%, P P V=55.6 \%, \mathrm{NPV}=87.8 \%, \mathrm{P}<0.001$

Table 3. The relationship between severity of hydronephrosis \& residual stone.

\begin{tabular}{|c|c|c|c|c|}
\hline \multirow{2}{*}{ Hydronephrosis } & \multicolumn{2}{|c|}{ Residual stone +ve } & \multicolumn{2}{c|}{ Residual stone -ve } \\
\cline { 2 - 5 } & $\leq 700$ & $>700$ & $\leq 700$ & $>700$ \\
\hline \multirow{2}{*}{ No } & 1 & 0 & 5 & 14 \\
\cline { 2 - 5 } & $(6.7 \%)$ & $(0 \%)$ & $(41.7 \%)$ & $(38.9 \%)$ \\
\hline \multirow{2}{*}{ Mild } & 10 & 3 & 6 & 14 \\
\cline { 2 - 6 } & $(66.7 \%)$ & $(60.0 \%)$ & $(50.0 \%)$ & $(38.9 \%)$ \\
\hline \multirow{2}{*}{ Moderate } & 3 & 2 & 1 & $(22.2 \%)$ \\
& $(20.0 \%)$ & $(40.0 \%)$ & $(8.3 \%)$ & 0 \\
\hline \multirow{2}{*}{ Severe } & 1 & 0 & 0 & \\
\hline
\end{tabular}




\begin{tabular}{|c|c|c|c|c|}
\hline & $(6.7 \%)$ & $(0 \%)$ & $(0 \%)$ & $(0 \%)$ \\
\hline P value & & & & \\
\hline
\end{tabular}

Table 4. The percentage of patients with residual stones according to stone density. Table 4 shows that a stone density $<700 \mathrm{HU}$ increased the risk of residual stones post PCNL by $3.77 \%$.

\begin{tabular}{|c|c|c|c|}
\hline & $>700$ & $\leq 700$ & Total \\
\hline No. & 41 & 27 & 68 \\
\hline Residual stone +ve & 5 & 15 & 20 \\
\hline & & & 29.42 \\
\hline
\end{tabular}

Table 5. Relationship between stone location \& presence of residual stone.

\begin{tabular}{|l|c|c|c|}
\hline \multirow{2}{*}{ Stone site } & \multicolumn{2}{|c|}{ Residual stone } & \multirow{2}{*}{ Total } \\
\cline { 2 - 4 } & positive & Negative & 4 \\
\hline lower calyx & 4 & 0 & 31 \\
\hline $\begin{array}{l}\text { Middle } \\
\text { calyx/renalpelvis }\end{array}$ & 5 & 26 & 21 \\
\hline $\begin{array}{l}\text { All(Staghorn } \\
\text { stone) }\end{array}$ & 7 & 17 & 12 \\
\hline Total & 20 & 5 & 68 \\
\hline
\end{tabular}

Table 6. Relationship between size of stone and residual rate among stones $>700 \mathrm{HU}$ density.

\begin{tabular}{|l|l|l|l|l|}
\hline residual & $\mathrm{N}$ & Mean size & & Std. Deviation \\
\hline
\end{tabular}




\begin{tabular}{|c|c|c|c|c|}
\hline positive & 5 & 50075.0000 & 15969.11081 & $<0.001$ \\
\hline negative & 36 & 16583.3333 & 18141.38422 & \\
\hline
\end{tabular}

\section{Discussion:}

Preoperative planning and a perfect percutaneous intervention are prerequisite for successful PCNL, Therefore, CT has become an important imaging method in the planning of a standard pre-PCNL and achieve higher success rates than those done without pre-PCNL CT. ${ }^{(15,16)}$ An additional benefit of pre-PCNL CT imaging is the calculation of the stone HU level. ${ }^{(17)}$

In this study, we assessed the predictive findings of unenhanced CT scans and on PCNL end results. First of all we found that an $\mathrm{HU}$ value lower than 700 is one of the most important factors that predicts failure of the PCNL procedure.

Huang and colleagues (18) have reported that when the density of the stones exceeded 800 in HU standards, all ureteral stones could be seen, whereas only $26 \%$ of the stones could be seen on plain radiography when the HU level was less than 200. Saw and colleagues ${ }^{(19)}$ reported that the $\mathrm{HU}$ value of the stone viewed in unenhanced CT scans can predict the fragility of the stone via ESWL. Pareek and coworkers ${ }^{(20)}$ reported in their clinical studies that $\mathrm{HU}$ values can predict the stone-free outcome after ESWL and showed that stones with lower HU values are associated with higher success rates.

In this study we found that a low HU value of less than 700 was associated with a higher rate of residual stones (75\%) increasing risk by 3.77 . This risk increased by 6.04 times when the stone was non-opaque. It has been suggested that this increase in residual stones is due to the fact that residual small stones cannot be viewed intraoperatively by fluoroscopic imaging. Turna and colleagues ${ }^{(21)}$ reported that a good PCNL outcome is also affected by the stone burden and the localization of the stones.

In the present study, one of the most important parameters that had an effect on the success rate was the localization of the stones. All four patients that had stones involving the upper calyx $(100 \%)$ had residual stones in follow up by US scanning. In contrast, only 5 (16\%) of the 31 patients with stones involving the lower calyx, 4 (19\%) of the 21 patients with middle calyceal/pelvic stone, and 7 (58\%) of the 12 patients with large staghorn stones involving all PCSs had residual stones on follow-up.

Regarding the degree of PCSs dilatation, it was noted that in the twenty patients with no hydronephrosis, only one patient had a residual stone (5\%), 13 patients out of the 33 patient with mild hydronephrosis $(39.4 \%), 5$ out of the 14 with moderate hydronephrosis (35.7\%) and only one patient with sever hydronephrosis had a residual stone on follow up $(100 \%)$. 


\section{Email:utjmed@utq.edu.iq}

Confirmation of our findings in larger, prospective studies may serve a useful tool for the selection of treatment modalities in patients with renal stones.

There are a number of constraints with imaging during PCNL. The contrast material instilled in the collecting system may decrease fluoroscopic image quality and become difficult to visualize fragmented stones on fluoroscopy if they do not have high HU density. It is possible to improve PCNL efficiency by flexible Nephoscopy. (22). Deveci and colleagues ${ }^{(23)}$ pointed out that struvite and uric acid stones have lower HU values than other types of stones. They observed a positive correlation between stone size and radio-density and reported higher $\mathrm{HU}$ values in larger stones regardless of the composition of the stone. Stones with low HU values are easily broken and shattered into pieces, and, when shattered, it is harder for these stones to be picked up completely. In addition, these low density stones are difficult to seen under fluoroscopy when they are diminished in size.

Another important finding of this study was the positive correlation between HU values and a decrease in hematocrit value. There is more bleeding as HU values increase, which can possibly be explained by the fact that stones with higher HU values are harder to break and require more energy and trauma during this process. These findings are comparable to a study by Arvind and colleagues. ${ }^{(24)}$ In this study six patients had a stone density higher than $1000 \mathrm{HU}$, four of them had significant bleeding and hematocrit reduction and there was more trauma.

Newman and colleagues (25) reported that the risk of recurrence of renal stone was higher in patients with residual stones after ESWL (21.6\% within one year of ESWL) than in those initially considered stone free $(8.4 \%)$. Graff and colleague (26) reported recurrent stones in $17.2 \%$ and $6.2 \%$ of patients, respectively, at a mean follow-up of 19.1 months.

Complete stone removal after PCNL is the goal for preventing stone regrowth however the success rate and residual stone detection varies with its definition, size ( $4 \mathrm{~mm}$ or more); and the imaging modality used. Stone-free rates have been reported to range from $40 \%$ to $90 \%$ after PCNL for renal calculi, and these rates were affected by stone number, size, nature (staghorn or non-staghorn), and operator skill. ${ }^{(27)}$ Most previous studies have reported relatively high success rates, ranging from $80 \%$ to $90 \%$, but these studies were in patients with residual stone of $4 \mathrm{~mm}$ considered as being stone free. In addition, most of these reports used plain abdominal films to evaluate residual stones or did not mention the imaging modality used. ${ }^{(28)}$

The need for routine post-operative CT imaging after PCNL remains controversial in spite of its effectiveness in detecting residual stones and decreasing the recurrence of renal stone. On the other hand, routine CT post PCNL is replaced by routine follow up with KUB radiography and US in asymptomatic patients with radio-opaque, non-struvite stones. ${ }^{(29)}$ 


\section{Email:utjmed@utq.edu.iq}

We observed a relatively low stonefree rate after PCNL (71\%), perhaps because we performed PCNL for larger stone burdens than other authors and because we reported tiny fragments on US as residual stones.

\section{Conclusion and \\ Recommendation:}

1. Pre PCNL native CT scan is mandatory not only for visualizing the retrorenal colon and excluding the presence of ureteric stones but also for stone parameters that predict the outcome of PCNL.

2. PCNL CT scan is recommended especially in patients at high risk of recurrent stone formation.

3. For those patients with complicated renal stones, access to stones of variable sizes and location can be reliably accomplished with $\mathrm{CT}$ urography (CTU) for accurate calyceal localization of each stone.

\section{References}

1. Smith RC, Levine J, Rosenfield AT. Helical CT of urinary tract stones. Epidemiology, origin, pathophysiology, diagnosis, and management. RadiolClin North Am. 1999; 37:911-52.

2. Chen MY, Zagoria RJ. Can noncontrast helical computed tomography replace intravenous urography for evaluation of patients with acute urinary tract colic? $J$ Emerg Med. 1999; 17:299-303.

3. Boulay I, Holtz P, Foley WD, White B, Begun FP. Ureteral calculi: diagnostic efficacy of helical CT and implications for treatment of patients.
Web Site: https://imed.utq.edu.iq

AJR Am J Roentgenol. 1999; 172:1485-90.

4. Assi Z, Platt JF, Francis IR, et al. Sensitivity of CT scout radiography and abdominal radiography for revealing ureteral calculi on helical CT: implications for radiologic follow-up. AJR Am J Roentgenol. Aug 2000; 175(2):333-7.

5. Miller OF, Rineer SK, Reichard SR, Buckley RG,Donovan MS, Graham IR et al. Prospective comparison of unenhanced spiral computed tomography and intravenous urogram in the evaluation of acute flank pain. Urology 1998;52:982-7.

6. Vieweg J, Teh C, Freed K, Leder RA, Smith RH, Nelson RH et al. Unenhanced helical computerized tomographyfor the evaluation of patients with acute flank pain. $J$ Urol 1998; 160:679-84.

7. Palmer JS, Donaher ER, O'Riordan MA, Dell KM. Diagnosis of pediatric urolithiasis: role of ultrasound and computerized tomography. J Urol 2005; 174:14131414.

8. Ketelslegers E, Van

Beers BE Urinary calculi: improved detection and characterization with thin-slice multidetector CT. Eur Radiol 2006; 16(1):161-165.

9. Lin WC

Uppot RN,Li CS, Hahn PF, Sahani D $\mathrm{V}$ Value of automated coronal reformations from 64-section multidetector row computerized tomography in the diagnosis of urinary stone disease. $J$ Urol 2007;178(3 pt 1):907-911 


\section{Email:utjmed@utq.edu.iq}

10. Metser U, Ghai S, Ong YY, L ockwood G, Radomski SB

Assessment of urinary tract calculi with 64- MDCT: the axial versus coronal plane. Am J Roentgenol 2009; 192(6):1509-1513. 11. Dalla Palma L, PozziMucelli R, Stacul F Present-day imaging of patients with renal colic. EurRadiol 2001; 11(1):4-17.

12. Saw KC, McAteer JA, Monga AG, Chua GT, Lingeman JE, Willia ms JC Jr.Helical CT of urinary calculi: effect of stone composition, stone size, and scan collimation. Am J Roentgenol 2000; 175(2):329-332.

13. Coşkun M, Tekin MI, Peşkirci oglu L, Tarhan NC, Ozkardeş H Spira lcomputed tomography: role in determination of chemical compositions of pure and mixed urinary stones - an in vitro study. Urology 2004; 64(2):237-240. 14. Gagnon RF, Alli AI, Edwardes MD, Watters AK, Tsoukas CM. Low urine $\mathrm{pH}$ is associated with reduced indinavir crystalluria in indinavir-treated HIV-infected individuals.

ClinNephrol.

2006;65:13-21.

15. Ghani KR, Patel U, Anson K. Computed tomography for percutaneous renal access. $J$ Endourol 2009; 23:1633-1639.

16. Gedik A, Tutus A, Kayan D, et al. Percutaneous nephrolithotomy in pediatric patients: Is computerized tomography a must? Urol Res 2011; 39:45-49.

17. Thiruchelvam N, Mostafid H, Ubhayakar G. Planning percutaneous nephrolithotomy using multidetector computed tomography urography, multiplanar reconstruction and threedimensional reformatting. BJU Int 2005; 95: 1280-1284.

18. Huang CC, Chuang CK, Wong YC, et al. Useful prediction of ureteral calculi visibility on abdominal radiographs based on calculi characteristics on unenhanced helical CT and CT scout radiographs. Int J ClinPract 2009; 63: 292-298.

19. Saw KC, McAteer JA, Fineberg NS, et al. Calcium stone fragility is predicted by helical CT attenuation values. J Endourol 2000; 14:471-474.

20. Pareek G, Armenakas NA, Fracchia JA. Hounsfield units on computerized tomography predict stone-free rates after extracorporeal shock wave lithotripsy. J Urol 2003; 169:1679-1681.

21. Turna B, Umul M, Demiryoguran $\mathrm{S}$, et al. How do increasing stone surface area and stone configuration affect overall outcome of percutaneous nephrolithotomy? J Endourol 2007; 21:34-43.

22. Ray AA, Ghiculete D, Pace KT, Honey RJ. Limitations to ultrasound in the detection and measurement of urinary tract calculi. Urology 2010; 76:295-300.

23. Deveci S, Cosxkun M, Tekin MI, and et al. Spiral computed tomography:Role in determination of chemical compositions of pure and mixed urinary stones - an in vitro study. Urology 2004; 64:237-240.

24. Arvind P. Ganpule, MRD. What's new in percutaneous nephrolithotomy. Arab Journal of Urology. 2012; 11:367-371 
25. Newman DM, Scott JW, Lingeman JE. Two-year follow-up of patientstreated with extracorporeal shock wave lithotripsy. J Endourol 1988; 2:163-171.

26. Graff J, Deidrichs W, Schulze H. Long-term followup in 1,003 extracorporealshock wave lithotripsy patients. J Urol 1988; 140:479-483.

27. Lim JK, Hyun JS, Chung KH. Cost and effectiveness of different treatment options for renal calculi larger than $2 \mathrm{~cm}$. Korean J Urol 2002; 43:454-458.

28. Lojanapiwat B. Previous open nephrolithotomy: Does it affect percutaneousnephrolithotomy techniques and outcome? J Endourol 2006; 20:17-20.

29. Sountoulides P, Metaxa L, Cindolo L. Is CT is mandatory for detection of residual stone fragments after PCNL? Journal of Endourology ; 27, Number 11, November 2013. 1341-1348. 


\section{استخدام عوامل المفراس متعدد الطبقات للتكهن في مدى نجاح عملية سحب حصاة الكليه بالناظور عن طريث الجلا}

زينة محمد عبد الجبار

حيار مهذي صالح

حيدر قاسم لفتة

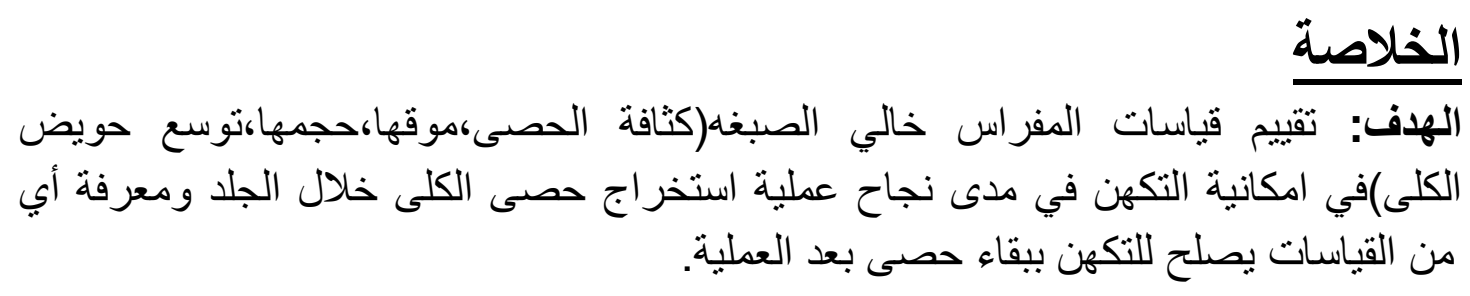

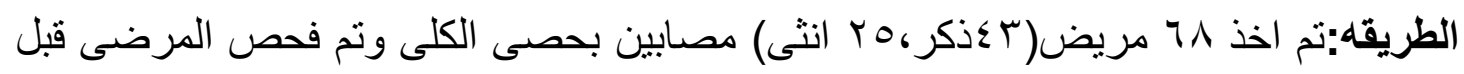

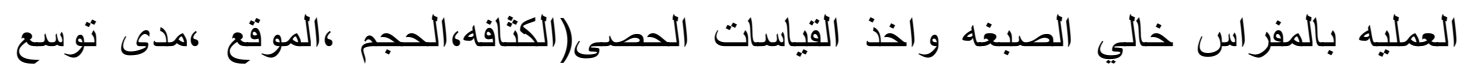

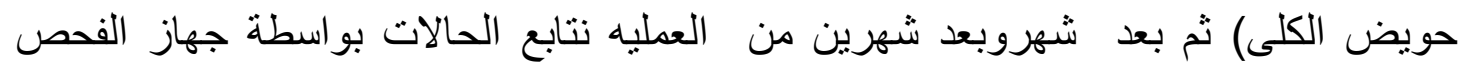
بالامواج فوق الصوتيه لمعرفة مدى وجود حصى باقيه ويحرى الفحص بواسطة طبيبين اثنين في نفس الوحده باعتماد عملم كتعريف حجمي للحيه لحصى الباقيه.

النتائج: قياسات الحصى المفر اسيه المتكهنه بامكانية بقاء الحصى بعد العمليه شملت الكثافه

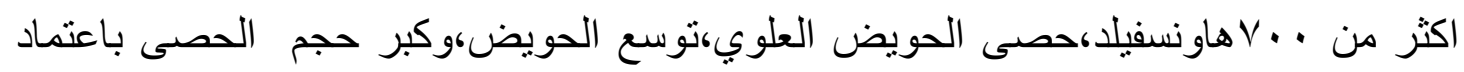
قيمة التكهن اكبرمن و هاحد بالالف. هوفئ.

الاستتتاج: ان المفر اس خالي الصبغه ضروري لاخذ قياسات الحصى التي تساعد على التكهن

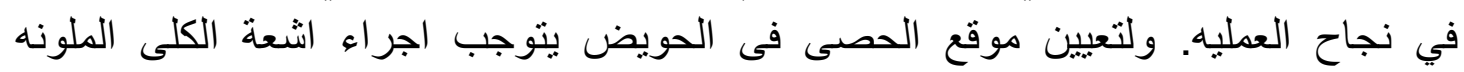
المفر اسيه. 
Thi-Qar Medical Journal (TQMJ): Vol.(13), No.(1), 2017 Email:utjmed@utq.edu.iq

Web Site: https://imed.utq.edu.iq 